\section{RELACIO $N$ ES}

Relaciones. Estudios de historia y sociedad ISSN: 0185-3929

relacion@colmich.edu.mx

El Colegio de Michoacán, A.C

México

Cortés Máximo, Juan Carlos

La desamortización de la propiedad indígena en una provincia mexicana. Los fines y efectos de la Ley

de 1827 sobre reparto de tierras comunales en Michoacán

Relaciones. Estudios de historia y sociedad, vol. XXXIV, núm. 134, 2013, pp. 263-301

El Colegio de Michoacán, A.C

Zamora, México

Disponible en: http://www.redalyc.org/articulo.oa?id=13726972010

- Cómo citar el artículo

Número completo

- Más información del artículo

- Página de la revista en redalyc.org

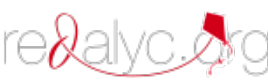

Sistema de Información Científica

Red de Revistas Científicas de América Latina, el Caribe, España y Portugal

Proyecto académico sin fines de lucro, desarrollado bajo la iniciativa de acceso abierto 


\title{
La desamortización de la propiedad indígena en una provincia mexicana. Los fines y efectos de la Ley de 1827 sobre reparto de tierras comunales en Michoacán
}

\author{
Juan Carlos Cortés Máximo* \\ UNIVERSIDAD MICHOACANA DE SAN NICOLÁS DE HIDALGO
}

El presente estudio abarca dos aspectos: primero, se mencionan las tierras que se dispusieron al reparto con base en el análisis de la Ley de 1827 y su Reglamento de 1828; segundo, se describen los efectos de la aplicación de dicha legislación en los pueblos indígenas. La aceptación u oposición al reparto estuvo marcada por el modo e intensidad con que fueron afectadas sus tierras a través del arriendo de una fracción o parte importante de ellas, debido a las disposiciones de los Reglamentos de comunidad elaborados en el periodo de aplicación de las llamadas "reformas borbónicas". Igualmente, la reacción de las autoridades y del común obedeció a la vigencia en la posesión y usufructo común de la tierra. No obstante la oposición al reparto bajo el argumento de que tenían poca tierra y de que carecían de fondos para cubrir los primeros gastos del proceso, demuestro que la Ley de 1827 sí se verificó en algunas poblaciones. Sostengo que los propósitos desamortizadores de la elite política estatal comenzaron a surtir efecto al liberarse la propiedad de la tierra vinculada a los pueblos indígenas.

(Reparto de tierras comunales, posesión comunal de la tierra, propiedad plena, derecho de vecindad)

\section{INTRODUCCIÓN}

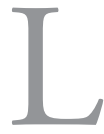

a legislatura michoacana, al igual que otras de la federación mexicana y de otras latitudes de Hispanoamérica, elaboraron leyes con el fin de transformar la tenencia comunal de la tierra a propiedad privada. La historiografía que aborda el tema cada

*meltiipajala@yahoo.com.mx 
vez utiliza con mayor frecuencia el concepto "desamortización” para referirse al proceso que se enmarca a partir de la segunda mitad del siglo XVIII y que continuó a lo largo del siglo XIX. ${ }^{1}$ En la península hispánica, la política de desamortización estuvo acompañada con la necesidad de hacer prosperar la economía agrícola a través del fomento de creación de pequeños propietarios; para lo cual, convenía convertir la propiedad amortizada en una "propiedad privada individual, única, libre y circulante". ${ }^{2}$

A fines del siglo XVIII, ese espíritu ilustrado permeó en las elites novohispanas. En el obispado de Michoacán, Manuel Abad y Queipo expuso que los naturales se encontraban en la "ignorancia" y "miseria” producto de las Leyes de Indias. Una de éstas, por ejemplo, impedía que los naturales se mezclaran con las "castas", lo cual era causa de que estuviesen privados de las "luces". Los indios producto de su gobierno "inútil y tirano" conservaban "costumbres, usos y supersticiones groseras". Este orden en los pueblos, según Abad y Queipo, lo mantenían ocho o diez indios viejos a expensas de otros, dominándolos "con el más puro despotismo". De modo que para propiciar su instrucción y promover su progreso que los apartaran de la "miseria”, se planteó como vía de solución: la división y distribución a título individual de las tierras de comunidad. Llama la atención la recomendación de este ilustrado de que se repartieran las tierras comunales "en dominio y propiedad" y dejar sólo los ejidos y los montes para usufructo común. Y es que al fina-

${ }^{1}$ Francisco Tomás y Valiente, "Reflexiones finales: entre el balance, la crítica y las sugerencias", Desamortización y Hacienda Pública, t. II, Madrid, Ministerio de Agricultura, pesca y alimentación, 1986, 786; Problemas agrarios y propiedad en México, siglos XVIII y XIX, Lecturas de Historia Mexicana 11, Introducción y selección de Margarita Menegus Borenemann, México, El Colegio de México, 1995, IX-Xx. De la misma autora, véase Los indios en la historia de México. Siglos XVI al XX: balance y perspectivas, Colección Herramientas para la Historia, México, Centro de Investigación y Docencia Económicas, Fondo de Cultura Económica, 2006, 49, 56 y 58.

${ }^{2}$ Citado por Alberto de la Hera, "Precedentes ilustrados del proceso desvinculador y desamortizador de bienes de manos muertas" en Han-Jürgen Prien y Rosa María Martínez de Codes, coords., El proceso desvinculador y desamortizador de bienes eclesiásticos y comunales en la América Española. Siglos XVIII y XIX, Cuadernos de Historia Latinoamericana núm. 7, Amsterdam, Asociación de Historiadores Latinoamericanistas Europeos, $1999,81,87$. 
lizar el siglo XvIII, según apreciación de Abad y Queipo, los pueblos estaban ceñidos a sus 600 varas, e indicó que sus integrantes no obtenían provecho individual de las tierras de "comunidades" sembradas. Abad y Queipo sostuvo que los naturales no conseguían beneficio alguno de las tierras que cultivaban, ya que los productos se invertían para financiar las necesidades festivas de los pueblos. En suma, el diagnóstico de Abad y Queipo consistió en que los indígenas carecían de una "propiedad individual", en virtud de que estaban circunscritos al fundo legal. ${ }^{3}$ De ahí el planteamiento de fraccionar las "tierras de comunidades" a fin de que cada uno tuviese una parcela para goce particular. Como ya ha dicho la historiografía existente, éste fue parte del precedente de ideas que después retomaron las elites liberales de los estados de la federación mexicana contra las tierras de comunidad.

\section{BREVE RECUENTO HISTORIOGRÁFICO Y DIRECTRICES AGRARIAS DEL CASO MICHOACANO}

Obvio que el plan desamortizador de la propiedad indígena fue un proceso de dimensión nacional e internacional. En este sentido, las acciones liberales del estado de Michoacán se inscriben en un horizonte mucho más amplio. Por ejemplo, visto desde el ámbito hispanoamericano, tenemos lo siguiente: en Venezuela, mediante el decreto de 24 de septiembre de 1810 y la promulgación de la Constitución Federal en diciembre de 1811, se promovió "el reparto en propiedad" de las tierras comunales. En Colombia también se ordenó la división de los terrenos usurpados, así como el arriendo de los excedentes. Con la ley de marzo de 1832 se buscó crear una masa de propietarios que pudiesen participar en el mercado de la fuerza labo-

${ }^{3}$ Manuel Abad y Queipo, Colección de escritos, Estudio introductorio y notas de Guadalupe Jiménez Codinach, México, Consejo Nacional para la Cultura y las Artes, 1994, 74-75; Enrique Florescano, "El problema agrario en los últimos años del virreinato, 1800-1821" en Problemas agrarios y propiedad en México. Siglos XVIII y XIX, México, El Colegio de México, 1995, 22-55. Este último texto también se puede ver en Enrique Florescano, Origen y desarrollo de los problemas agrarios de México, 1500-1821, Séptima edición, México, Era, 1984, 131-158. 
ral y en la movilidad de la propiedad indígena. Dos años después, se reiteró la privatización de los inmuebles colectivos con la indicación de que no se atendieran las reclamaciones que los indígenas realizaran en los tribunales en torno a que no se repartieran las tierras. ${ }^{4}$

En esa misma línea de desmantelar la posesión comunal de la tierra, los gobernantes de Bolivia a través de la ley del 6 de abril de 1824, especificaron que las tierras debían compartirse entre los indígenas como "terrenos propios". 5 En Perú, después de la ofensiva liberal desamortizadora, el Estado frenó el proceso a partir de $1827 \mathrm{al}$ reconocer que los pueblos indígenas tenían derecho a poseer sus tierras con "plena posesión soberana", es decir, a tener el dominio útil. Las comunidades argumentaron que para cumplir con el impuesto directo, debían conservar sus tierras colectivas a fin de asegurar los pagos respectivos. ${ }^{6}$ Fuera de estos planes y acciones, los estudios hispanoamericanos referidos no abundan en los efectos que generó la aplicación de las primeras leyes de reparto de los recién fundados Estado nación. Una de las investigaciones citadas, correspondiente a las tierras comunales en Venezuela y Colombia, establece que los indígenas se opusieron al reparto por vías pacíficas y violentas, pero sin más detalles al respecto. ${ }^{7}$

Respecto a la historiografía mexicana que aborda las primeras acciones desamortizadoras en la región, ésta establece que los gobiernos de los estados buscaron transformar la tenencia comunal de la tierra a propiedad privada. Obviamente que estamos de acuerdo con este señalamiento, sin embargo es importante, como lo propone Margarita Menegus, precisar el tipo de tierra que las legislaturas

${ }^{4}$ Edda O. Samudio, "La transformación de la propiedad comunal en Venezuela y Colombia a través del proceso de desvinculación de bienes" en, Han-Jürgen Prien y Rosa María Martínez de Codes, coords., El proceso..., pp. 157-188.

${ }^{5}$ Marie Danielle Demelas Bohy, "La desvinculación de las tierras comunales en Bolivia, siglos XIX-Xx” en, Han-Jürgen Prien y Rosa María Martínez de Codes, coords., El proceso..., pp. 129-155.

${ }^{6}$ Jean Piel, "Problemática de las desamortizaciones en Hispanoamérica en el siglo XIX (algunas consideraciones desde el punto de vista socioeconómico y, por tanto, ideológico)" El proceso..., pp. 97-128.

${ }^{7}$ Edda O. Samudio, “La transformación de la propiedad”, en Han-Jürgen Prien y Rosa María Martínez de Codes, coords., El proceso..., pp. 157-188. 
de los estados se propusieron afectar. ${ }^{8}$ En 1824 , la elite política de Oaxaca con el fin de alentar la producción agrícola ordenó el reparto de tierras comunales "con igualdad entre todos los ciudadanos". Con esta disposición se pretendía borrar la desigualdad que había entre los pueblos respecto a la propiedad de la tierra, pues mientras unos tenían extensas tierras que no cultivaban, otros carecían de ellas, y aquellos que las poseían no eran susceptibles para la agricultura. En los años sucesivos, los legisladores oaxaqueños continuaron con opiniones en contra de la propiedad común, al tiempo que mandaban recabar información agraria por conducto de los jefes de Departamento que les sirviera para formular una ley sobre los "terrenos comunes".?

En 1825, los diputados de Jalisco reconocieron que los indios eran propietarios de los terrenos, casas y solares que poseían, los cuales podían disponer a su conveniencia, únicamente con la prohibición de no enajenarlas "en favor de manos muertas". Fue hasta septiembre de 1827 que la legislación jalisciense ordenó el reparto de tierras que los pueblos indios habían comprado. Cinco años después, en marzo de 1832, el congreso legisló acerca del reparto de aquellas tierras que hasta ese momento estaban exceptuadas de leyes anteriores. ${ }^{10}$ También hacia 1827 la legislatura del estado de México acordó proceder gubernativamente al "repartimiento de tierras", de acuerdo a las leyes de la materia. ${ }^{11}$

${ }^{8}$ Margarita Menegus, Los indios en la historia, p. 55.

${ }^{9}$ Luis Alberto Arrioja Díaz Viruell, "La desamortización de la propiedad comunal en la Sierra Mixe (Oaxaca): El caso de San Cristóbal Chichicastepec y Santa María Mixistlán, 1856-1863”, en Carlos Sánchez Silva, coord., La desamortización civil en Oaxaca, México, Universidad Autónoma "Benito Juárez" de Oaxaca, Universidad Autónoma Metropolitana, 2007, 141-146.

${ }^{10}$ Mario Aldana Rendón, "La privatización de los terrenos comunales en Jalisco. Los primeros pasos. 1821-1833”, Alejandra García Quintanilla y Abel Juárez, coords., Los lugares y los tiempos. Ensayos sobre las estructuras regionales del siglo XIX en México, México, Consejo Mexicano de Ciencias Sociales, A. C., Universidad Veracruzana, Universidad Autónoma de Nuevo León, Editorial Nuestro Tiempo, 1989, 50-82.

${ }^{11}$ Rina Ortiz Peralta, "Inexistentes por decreto: Disposiciones legislativas sobre los pueblos de indios en el siglo xIx. El caso de Hidalgo", en Antonio Escobar, coord., Indio, nación y comunidad en el México del siglo XIX, México, Centro de Estudios Mexicanos y Centroamericanos, Centro de Investigaciones y Estudios Superiores en Antropología Social, 1993, 153-169; Margarita Menegus establece la distinción del estado de México 
Por su parte, los diputados de la federación mexicana aprobaron el proyecto de ley en el que se ordenaba la "entrega" de los bienes a los apoderados de los pueblos para que las conservaran "pro indiviso", en tanto el "gobierno supremo" elaborara el reglamento para el reparto de "todos los bienes de indígenas". El Distrito de México, siguiendo el espíritu del congreso federal, dispuso la entrega de los bienes a los pueblos, $\mathrm{o}$ bien a sus apoderados. ${ }^{12}$

En la región, la historiografía michoacana generada entre 1976 y 2004 respecto al proceso desamortizador, sostuvo que la ley de 1827 de reparto de tierras no se aplicó por la propia ambigüedad de ésta. ${ }^{13}$ Fue común leer frases como: "La ley no llegó a tener muchos resultados", ley y reglamento "no parecen haber tenido mucho efecto", "no fue mucho lo que se logró con la primera legislación". Los estudiosos arribaron a ese tipo de señalamientos en virtud a que básicamente utilizaron documentos del ramo de Hijuelas proveniente del Archivo Histórico del Poder Ejecutivo, información muy rica para el periodo de la República restaurada y el Porfiriato, etapas en las

de recudir "todas las tierras de los pueblos" como propios, a diferencia de estados como Michoacán de ordenar el reparto, "La desamortización de bienes comunales y municipales en el Valle de Toluca (1800-1854)", en Siglo XIX. Cuadernos de Historia, año Iv, núm. 12, mayo-agosto de 1995, 7-27.

${ }^{12}$ Andrés Lira González, Comunidades indígenas frente a la ciudad de México, México, El Colegio de Michoacán, El Colegio de México, 1983, 173-174.

${ }^{13}$ Gerardo Sánchez Díaz, El suroeste de Michoacán. Estructura económico-social 18211851, Colección Historia Nuestra 2, México, Universidad Michoacana de San Nicolás de Hidalgo, 1979, 53-46; Moisés Franco Mendoza, "La desamortización de las tierras de las comunidades indígenas de Michoacán” en Pedro Carrasco, coord., La sociedad indigena en el centro y occidente de México, Zamora, El Colegio de Michoacán, 1986, 169188; Robert J. Knowlton, "La división de las tierras durante el siglo xIx: el caso de Michoacán” en Problemas agrarios y propiedad en México, siglos XVIII y XIX, México, El Colegio de México, 1995, 124; Sergio García Ávila refiere que "las disposiciones no tuvieron aplicación" como consecuencia de la "inestabilidad política", en "Desintegración de las comunidades indígenas de Morelia”, en Estudios de historia moderna y contemporánea de México, vol. xv, 1992, 58. García Ávila en reciente estudio sostiene que se realizó un "reparto parcial", La politica liberal y las comunidades indigenas en Michoacán: de las Reformas Borbónicas a la primera república federal, México, unAm, Facultad de Filosofía y Letras, Tesis de Doctor en Historia, 2006. Para un recuento de las leyes emitidas en Michoacán puede verse el estudio de Ángel Gutiérrez, Las comunidades agrarias michoacanas. Siglos XIX Y XX, Morelia, Universidad Michoacana de San Nicolás de Hidalgo, Archivo Histórico, 1998. 
cuales sí se cuenta con experiencias de reparto de la propiedad comunal. Con base en ese corpus documental, los investigadores concluyeron que la primera disposición no se había llevado a la práctica debido a que la mayoría de los pueblos analizados databan de aquellos dos periodos.

Ante ese panorama sintético y parcial en Hispanoamérica, México y Michoacán, enfatizo tres aspectos acerca del presente artículo:

1) Que derivado del balance en Hispanoamérica, el estudio circunscrito en la provincia de Michoacán cobra relevancia puesto que pongo al descubierto la maraña legal elaborada por la elite gobernante y muestro las diversas reacciones de los actores indígenas al ejecutarse la ley de reparto de 1827.

2) Los estudios sobre las primeras acciones privatizadoras de las tierras de comunidad en México establecen que las legislaturas de los estados mantuvieron el espíritu de repartir "todos los bienes de indígenas", pero otros son pocos claros. A este respecto, la historiografía michoacana sostiene que el Congreso del Estado especificó el propósito de repartir todas las tierras en manos de los indígenas, pero otros señalan que no fue así, sino sólo una fracción reducida. Ante ese descuido de la literatura mexicana y provincial, para el caso michoacano preciso los terrenos que se dispusieron al reparto.

3) A partir de la valoración historiográfica michoacana sobre la nula aplicación de la primera acción desamortizadora, expongo los efectos de la ley de 1827, en especial explico las problemáticas y polémicas que se desprendieron en torno a las personas que debían ser las beneficiadas en el reparto. Describo las dificultades derivadas del perfil y del número de personas que integrarían las comisiones de reparto. Y finalmente, señalo los factores que impidieron la transformación de las tierras de posesión comunal a propiedad privada. No obstante este último punto, la idea que pretendemos demostrar estriba en que la ley de 1827 sí se aplicó en ciertos pueblos, lo que reavivó problemas al interior de ellos con relación a los derechos de vecindad que adquirían los indios y no indios provenientes de otros poblados. Arribé a estas apreciaciones a partir de la consulta de nuevos repositorios documentales, a saber: el Archivo Histórico del H. Congreso del Estado de Michoacán y el Archivo Histórico Municipal de Morelia. 
Después de que la elite estatal no reconoció a las antiguas repúblicas de naturales y, en cambio, promovió la creación de ayuntamientos, ${ }^{14}$ la siguiente tarea que ocupó a los diputados consistió en elaborar una ley en relación con las tierras de comunidad. Al igual como ocurrió con la supresión de las repúblicas naturales, la opinión de los legisladores fue unánime respecto a crear una ley para repartir los bienes de comunidad.

Durante el periodo de la Diputación Provincial de Valladolid de Michoacán (1822-1823), varios pueblos indígenas solicitaron la devolución de aquellos bienes, que otrora el subdelegado había arrendado, incluso, a través del reparto; es decir, que plantearon la recuperación de aquellas tierras mediante la división en fracciones y distribución de las mismas entre los jefes de familia. Sin embargo, las respuestas fueron desfavorables para los indígenas; de modo que los problemas relacionados con la recuperación, el arrendamiento y la administración que de ellas hacían los ayuntamientos persistieron al comenzar a sesionar el congreso constituyente michoacano en abril de 1824. Cuando los diputados abordaron el tema agrario, los bienes de comunidad se encontraban como parte de los fondos de los 99 ayuntamientos gaditanos. En otra investigación expuse los términos en los cuales se dio la discusión entre los legisladores, ${ }^{15}$

${ }^{14}$ Para mayores detalles de la discusión entre los diputados del primer Congreso Constituyente en torno a la propuesta de ley municipal y los pueblos que perdieron la categoría de ayuntamiento, consúltese: Juan Carlos Cortés Máximo, "Ayuntamientos michoacanos: separación y sujeción de pueblos indios, 1820-1827” en Tzintzun, Revista de Estudios Históricos, núm. 45, enero-junio de 2007, 33-64. En otro estudio establecí que ciertos pueblos del oriente michoacano perdieron jurídicamente sus antiguos gobiernos de "república" con motivo de su incursión al movimiento insurgente, pero a partir de 1820, algunos de ellos crearon sus gobiernos constitucionales. Véase el estudio de mi autoría, "Separación de sujetos, guerra insurgente y ayuntamientos gaditanos: los pueblos indios en el Oriente de Michoacán, 1750-1824” en Moisés Guzmán Pérez, coord., Imaginarios, guerra y nación, México, Universidad Michoacana de San Nicolás de Hidalgo, 2007, 77-124.

${ }^{15}$ Juan Carlos Cortés Máximo, De república de indios a ayuntamientos constitucionales: pueblos cabeceras y sujetos de Michoacán, 1740-1831, Tesis de Doctorado en Historia, Zamora, El Colegio de Michoacán, 2005, 316, 317. 
aquí únicamente retomo el señalamiento de José Trinidad Salgado, quien planteó que una parte de los bienes comunales debían pasar a los ayuntamientos como parte de sus fondos y otras debían repartirse en parcelas individuales entre indios, mestizos y mulatos. Otra propuesta de los diputados consistió en que los bienes de comunidad se devolvieran a las "primitivas familias indígenas", ya no para su usufructo colectivo sino para que en lo sucesivo las disfrutaran en forma individual. Después de algunas discusiones, finalmente se convino en esta última.

La ley de reparto se discutió y aprobó en 1825 , pero fue hasta el segundo Congreso Constitucional (1827-1828) que se dio a conocer el decreto con algunos artículos adicionales. La ley de reparto decretada el 18 de enero de 1827 fue clara desde el principio, al definir que los terrenos repartibles eran aquellos "bienes conocidos con el nombre de comunidad", esto es, los terrenos que antiguamente arrendaban los subdelegados, y que al crearse los ayuntamientos gaditanos, habían pasado a éstos la administración de las tierras y rentas de comunidad. ${ }^{16}$

Al comenzar la vida republicana de México, los pueblos de indígenas, aparte de los bienes de comunidad que en calidad de excedentes se habían arrendado por el gobierno borbónico, también disfrutaban tierras catalogadas de fundo legal donde los indios y "avecindados" españoles, mestizos y mulatos tenían sus casas y solares. El asiento de estos grupos en los pueblos indios databa del periodo colonial, sobre todo con mayor acento a partir de la segunda mitad del siglo xviıI. ${ }^{17} \mathrm{Al}$ paso de los años, los españoles y sus descendientes se afianzaron como dueños de los solares. Como explica-

${ }^{16}$ Igualmente se estipuló que el gobernador con ayuda del Consejo de Gobierno debían elaborar el reglamento para el reparto de tierras de comunidad. Actas y decretos del Congreso Constituyente del Estado de Michoacán, t. II compilación, prólogo y notas de Xavier Tavera Alfaro, Morelia, Universidad Michoacana de San Nicolás de Hidalgo, sesión del 12 de junio de 1825, 396.

${ }^{17}$ Naoki Yasumura estudió la incursión de españoles en Numarán, en "El proceso de civilización desde abajo: el caso de un pueblo del bajío michoacano a finales de la colonia", texto presentado por el autor para su discusión en la reunión del Grupo K'waniskuyarani de Estudiosos del Pueblo P'urhépecha, en el Ex Colegio Jesuita de Pátzcuaro, el 26 de enero de 2008. 
ré más adelante, el Reglamento de reparto de tierras de 1828 respetó los solares que ocupaban los indios y los que poseían los vecinos, aún llamados "gente de razón”. El fundo legal también incluyó tierras laborables que se encontraban en las afueras de los pueblos, inscritas en las 600 varas por los cuatro puntos cardinales tomando como base de medición la última casa del pueblo. ${ }^{18}$

Aparte del fundo legal, los naturales disponían de montes y pastizales, donde los indios extraían leña, barro y otros recursos naturales para sus actividades domésticas, artesanales y fines comerciales. El otro género de tierras que poseían eran las de repartimiento, distribuidas en parcelas familiares, en las cuales los indios cultivaban alimentos básicos (maíz, trigo, frijol, calabaza), o bien productos destinados al comercio local (arroz, caña dulce); esto último sucedió con algunos pueblos ubicados en la Tierra Caliente de Tepalcatepec. ${ }^{19}$ En consecuencia, cada jefe de familia contaba con una fracción de tierra para la siembra. Internamente, los pueblos de indios manejaban y poseían fracciones en forma familiar, pero si por algún motivo dejaban de participar en el servicio personal y en los pagos para las festividades cívicas y religiosas, ya fuera por ausencia u otro motivo, el gobierno indígena ordenaba que pasaran nuevamente a figurar como parte del patrimonio comunal. En otras palabras, internamente los indios tenían derecho al usufructo de las tierras de común repartimiento, mas no a la propiedad plena. En este mismo sentido de aprovechamiento, se encontraban las tierras de pastizal (como parte de los ejidos) y los cerros.

A manera de síntesis, los pueblos indígenas tenían solares, huertos y fracciones de cultivo (inscritas en el fundo legal), parcelas de uso familiar (las tierras de repartimiento), terrenos de pastizal (parte de los ejidos) y los cerros. En éstos, los indígenas extraían diversos recursos naturales que aprovechaban en forma colectiva. Parte de esa riqueza fue aquella que Juan José Martínez de Lejarza denominó como "bienes de comunidad", los cuales desglosó en "13 Haciendas

${ }^{18}$ Marta Terán, ;Que muera el mal gobierno! Las reformas borbónicas en los pueblos michoacanos y el levantamiento indígena de 1810, México, El Colegio de México, Tesis de Doctor en Historia, 1995, 237-239.

${ }^{19}$ Gerardo Sánchez Díaz, El suroeste de Michoacán, pp. 65, 66, 70. 
de labor, 370 Ranchos considerables, 5 Estancias de ganado, 5 Huertas de árboles frutales, 843 Solares, dentro y fuera de los Pueblos, 11 Potreros grandes, 74 y una cuartilla fanegas de sembradura de maíz en varios pedazos de tierra, 183 leguas cuadradas de tierras pastales (y) 29, 762 pesos 5 y medio en capitales la mayor parte perdidos". ${ }^{20}$ Como es notorio, solares, huertas, potreros, parcelas para la siembra, haciendas y ranchos de labor, tierras de pastizal y estancias de ganado, se inscribían en la categoría del fundo legal, los ejidos y los propios.

Dichos bienes, al igual que el resto de las tierras que estaban en manos del común, constituían la "propiedad particular" de los pueblos de indios. Es decir, que la corporación indígena era propietaria del conjunto de tierras de comunidad, mismas que estaban bajo el rango de amortizadas. Esto significa que la propiedad de la tierra estaba vinculada a un cuerpo civil. Si este principio lo aplicamos a los pueblos de indios, la propiedad comunal era para goce perpetuo de las familias indígenas, y de ningún modo debía enajenarse. De modo que personas externas a la comunidad estaban imposibilitadas de acceder a ella. Internamente, los indígenas transferían solares y parcelas de cultivo entre sí, es decir, que otorgaban el derecho a otros comuneros a percibir los frutos de la tierra concedida, más no podían venderla como propietario pleno. ${ }^{21}$ De los montes y pastos, los indígenas tenían derecho a extraer los recursos y los productos que proveía nana Cueráperi (la madre creadora). De manera que el común, como sus autoridades, sabían el derecho que tenían los "hijos del Pueblo" sobre los terrenos de repartimiento y de usufructo común.

Para que los jefes de familia mantuvieran el disfrute de las parcelas y los recursos naturales referidos, debían cumplir con los servi-

${ }^{20}$ Juan José Martínez de Lejarza, Análisis estadistico de la provincia de Michoacán en 1822, Colección "Estudios Michoacanos" Iv, Introducción y notas de Xavier Tavera Alfaro, 2a edición, Morelia, Fímax Publicistas, 1974 [1824], tabla num. 7. "Estado general de los bienes llamados de comunidad que poseen los pueblos de la Provincia de Michuacán en sus respectivos Partidos, los cuales administran sus Ayuntamientos o Municipalidades bajo la inspección de la Diputación Provincial".

${ }^{21}$ Joaquín Escriche, Diccionario razonado de legislación y jurisprudencia, t. I, México, Librería de la Vda. De C. Bouret, 1920, 158, 567 y 568; t. II, p. 1359. 
cios y pagos personales a fin de sostener el orden festivo cívico y religioso de la comunidad. Si por algún motivo faltaban a sus obligaciones, el gobierno indígena podía suspenderlos y apartarlos de la tierra de cultivo al grado de negarle el uso de los pastos y demás recursos comunales. A partir de ese momento dicha fracción volvía a formar parte del patrimonio comunal. Las parcelas se reintegraban a su antiguo poseedor cuando cumplía de nueva cuenta con los pagos y servicios como "hijo del Pueblo". ${ }^{22}$ De esta manera, el común de indígenas poseía y usufructuaba las tierras de comunidad al comienzo de la vida independiente de la nación mexicana.

Cuando se publicó la Ley y el Reglamento michoacanos, ambos resultaron sugerentes, ya que los jefes de familia asumirían el "pleno" derecho sobre la tierra dividida, además de que podían enajenarla a indígenas y no indígenas una vez cumplidos los cuatro años de haberse ejecutado el reparto. Dichos ordenamientos fueron de gran relevancia en virtud de que se planteó la transformación de la propiedad común a propiedad privada, otorgándoles a los indígenas derecho absoluto sobre la fracción repartida. Dicho de otra manera, los indígenas no sólo tendrían el derecho de gozar los frutos de la parcela como antaño, ahora tendrían el dominio "pleno" con libertad de otorgarla en venta.

El artículo 5 de la ley de reparto de 1827 especificó que los terrenos para fraccionarse en parcelas privadas debían ser aquellas que estaban en "arrendamiento con el título de sobrantes de comunidad". ${ }^{23}$ Estos bienes fueron los que detalló Martínez de Lejarza hacia 1822, mismos que para principios de 1827 se encontraban como parte de los ayuntamientos. Con dicho decreto, se advierte la intención de los legisladores de resolver las múltiples quejas que desde el periodo de la Diputación Provincial de Valladolid de Michoacán

${ }^{22}$ Una apreciación en el sentido expuesto se puede ver en Margarita Menegus, $\mathrm{La}$ Mixteca Baja. Entre la revolución y la reforma. Cacicazgo, territorialidad y gobierno. Siglos XVIII-XIX, México, Universidad Autónoma Benito Juárez de Oaxaca, Universidad Autónoma Metropolitana, H. Congreso del Estado de Oaxaca, 2009, 114.

${ }^{23}$ Ley núm. 23 de 18 de enero de 1827, en Amador Coromina, Recopilación de leyes, decretos, reglamentos y circulares expedidas en el estado de Michoacán, t. II, vol. 1, Morelia, Imprenta de los Hijos de I. Arango, 1886, 61, 62. 
habían expuesto los indígenas respecto al manejo que de ellas hacían los ayuntamientos. El "Reglamento para la partición de las tierras de comunidad entre los descendientes de las primitivas familias" del 15 de febrero de 1828, reafirmó el propósito de la elite política de repartir aquellos bienes al ordenarse en su artículo 5 la elaboración de una lista de tierras que "están en arrendamiento con título de sobrantes de comunidad". ${ }^{24}$ Cabe apuntar que el Reglamento fue redactado por los integrantes del Consejo de gobierno, instancia que a través del secretario, José María Paulín, se entregó al ejecutivo estatal con fecha de 25 de enero de 1828 , quien semanas después ordenó su publicación y aplicación.

En el mismo artículo 5, se precisó realizar otra lista de terrenos que "disfrutan los naturales", con lo cual se quería indicar que la tierra por repartir era la que propiamente usufructuaban los indígenas a título individual: propiedades que el gobierno colonial definió como de repartimiento. Hasta aquí, las tierras por dividir fueron las de repartimiento, las huertas, parcelas para la siembra, haciendas, tierras de pastizal, estancias de ganado, entre otras, catalogadas como "excedentes de comunidad". Esta frase fue utilizada por la elite estatal para indicar las tierras que anteriormente arrendaban los subdelegados, bienes que al ejecutarse la ley de 1827 estaban bajo la administración de los ayuntamientos como ya se expuso.

$\mathrm{Si}$ bien los legisladores consideraron incluir en el reparto únicamente los "sobrantes de de comunidad", el Consejo de Gobierno, a quien correspondió elaborar el Reglamento de 1828, reafirmó como tierras repartibles las de común repartimiento, incluso las que habían sido vendidas, empeñadas, arrendadas y, en general, enajenadas por las autoridades indígenas sin la autorización del gobierno superior y, siempre y cuando, se constara "la ilegalidad de dichos contratos" por no haberse sujetado a las "leyes y reglamentos". ${ }^{25}$ En otras palabras, la elite liberal pretendió regularizar el acceso y el usu-

24 "Reglamento para la partición de tierras de comunidad entre los descendientes de las primitivas familias" de 15 de febrero de 1828, Amador Coromina, Recopilación de leyes.., vol. 1, t. III, 1886, 30.

${ }^{25}$ Artículo 14 del Reglamento, Coromina, A., Recopilación de leyes..., vol. 1, t. III, $1886,31$. 
fructo de la propiedad entre indígenas, cuyas ventas o concesiones no se habían hecho conforme a las leyes antiguas. Hasta aquí, los miembros del Consejo no se apartaron de la política de dividir los terrenos de comunidad en parcelas de propiedad individual, y señalaron que no tendrían validez todas aquellas transacciones realizadas por los indígenas, si éstas no se habían realizado acorde a las "leyes y reglamentos".

El artículo 13 del Reglamento de 1828 ordenó el reparto de tierras de siembra y las susceptibles de cultivarse con el "trabajo e industria”; además de que se encomendó a la comisión repartidora reconocer las "puramente pastales, los malpaises y cerros". Si parte de los ejidos, lo constituían los pastizales, podemos decir que el Consejo de gobierno fue más allá de la Ley de 1827 al considerar en el Reglamento de reparto una parte de los ejidos (pastizales) e incluso los malpaíses y cerros. Por otro lado, el artículo 14 aclaró que aquellas tierras que estuviesen arrendadas, de acuerdo a la legislación de la materia, debían cumplir los términos convenidos en el contrato de arriendo. No obstante que se ordenó el reparto entre los jefes de familia, éstos no podían entrar en dominio de ellas, sino hasta que finalizara el arrendamiento; entre tanto, los indígenas disfrutarían una parte de la renta de acuerdo a la fracción que le había de corresponder. ${ }^{26}$

Para evitar que los ayuntamientos volvieran a suscribir nuevos arriendos, que fue el origen de varias quejas e inconformidades expresadas por los pueblos indígenas, se prohibió a dichas instituciones celebrar nuevos arrendamientos. El artículo 28 ordenó que no tendrían validez los nuevos contratos después de "publicado el decreto" (se refieren al Reglamento de 15 de febrero de 1828). El artículo 15 dispuso que las tierras en proceso de litigio, pero en posesión de los pueblos, también se sujetarían al reparto. ${ }^{27}$ En resumen, las tierras por repartirse fueron: 1) las arrendadas; 2) las que de forma ilícita habían arrendado, vendido, empeñado, cedido y, en general,

${ }^{26}$ Artículo 27 del Reglamento, A. Coromina, Recopilación de leyes., vol. 1, t. III, $1886,33$.

${ }^{27}$ Idem. También véase: J. C. Cortés Máximo, De república de indios a ayuntamientos constitucionales, p. 318. 
enajenado sin previa autorización de la autoridad superior, catalogadas como "sobrantes de comunidad"; 3) las que usufructuaban los indios de manera individual (repartimiento); y 4) las propiedades que estuviesen en litigio con algún pueblo o hacienda limítrofe, pero en posesión de los indígenas. También los pastizales (ejido), los malpaíses y los cerros.

Sobre la Ley de 1827 y el Reglamento de 1828 existen dos posturas en la historiografía local, una propone que "todos" los bienes de comunidad fueran dispuestos al reparto ${ }^{28}$ y otra que sostiene que la legislación fue moderada porque no se pronunció por "la destrucción absoluta de las tierras comunales". ${ }^{29}$ Como ya vimos, la Ley y el Reglamento no fueron explícitos en torno a la tierra que pretendían repartir, me refiero a las denominaciones de fundo legal, ejidos y de repartimiento, pero podemos afirmar que la elite política michoacana, en primer lugar, buscó fraccionar los "sobrantes" de comunidad con la idea de resolver los problemas latentes respecto al arriendo y el control que de ellos tenían los ayuntamientos. Y fue un ańo después, en el Reglamento de 1828, que se ordenó el reparto de las tierras de repartimiento, las litigiosas, los pastizales, los malpaíses y los cerros. Es decir, que en el fondo los legisladores y después el Consejo de gobierno, sí se propusieron transformar la forma en que los indígenas disfrutaban sus tierras y hacían uso de los pastos y ceros, ya no en forma comunal sino en forma privada.

Por su parte, los terrenos que quedaron fuera del reparto fueron "los solares ocupados, ya por los que se llaman de razón, ya por los indígenas". Con ello, la elite política admitía la presencia de españoles y mestizos en los pueblos de indios; les reconocía el derecho de mantenerse como poseedores de los solares, pero advirtieron que los pagos que por derecho de ocupación, anteriormente cobrados y canalizados a las autoridades indígenas, en adelante se depositarían en las tesorerías de los ayuntamientos. Con en el paso del tiempo, los vecinos espańoles y mestizos se convirtieron en los dueńos de los solares.

${ }^{28}$ S. García Ávila, La politica liberal y las comunidades indígenas...

${ }^{29} \mathrm{M}$. Franco Mendoza, La ley y la costumbre en la cañada de los once pueblos, Zamora, El Colegio de Michoacán, 1997. 
No debemos olvidar que los pueblos de indios michoacanos perdieron el control de una parte importante de sus bienes durante la aplicación de la Real Ordenanza de Intendentes. Esta situación así se mantuvo durante la guerra por la emancipación de Nueva Espańa, aunque algunos pueblos recobraron parte de ellos mientras duró el dominio insurgente. Al pacificarse las zonas rebeldes, las autoridades de la intendencia reactivaron la política de arrendamiento de los excedentes de comunidad. Por lo tanto, los pueblos indígenas perdían el control de dichas tierras. Con la fundación de los ayuntamientos gaditanos y los ajustes de éstos contenidos en la Constitución del Estado de Michoacán, los terrenos de comunidad siguieron formando parte los consejos municipales. De manera que a cuatro años de haberse fundado la nación mexicana, los pueblos y las comunidades indígenas no poseían ni mucho menos usufructuaban las tierras que, antes de los Reglamentos borbónicos de comunidad, sí administraban y usufructuaban.

De ahí que la ley de reparto se convirtió en el instrumento para que ciertas comunidades recuperaran aquellos terrenos que antańo el subdelegado arrendaba. Si se trataba de dividir los ranchos, potreros y demás terrenos que desde años atrás ya no estaban en manos del común de naturales, desde luego que a éstos interesó el reparto. Por ello ciertas poblaciones aceptaron el reparto de tierras, aunque fuese para mantenerlas en propiedad privada y no más bajo los principios comunales. Por ejemplo, los pueblos de Chiquimitío y Santiago Undameo midieron y repartieron las "tierras de comunidad" en parcelas para goce individual y privado de cada indígena.

Lo ocurrido en Undameo fue interesante en virtud de que los habitantes, de ascendencia matlazinca, transformaron su república de naturales en ayuntamiento constitucional durante el segundo momento de vigencia de la carta gaditana con el fin de hacerse cargo de aquellas tierras que habían estado en arrendamiento y, al mismo tiempo, proteger los otros tipos de tierra comunal (fundo legal, ejidos y de repartimiento). ${ }^{30}$ Sin embargo, con la reforma de ley sobre

${ }^{30}$ Felipe Castro, "Undameo: La contraofensiva agraria de una comunidad en el siglo XVIII" en Carlos Paredes Martínez, coord., Historia y sociedad. Ensayos del seminario de 
creación y permanencia de ayuntamientos de 1825, Undameo perdió el estatus de cabecera de gobierno al reducirse como tenencia del ayuntamiento de Tiripetío. Desde luego que ello los puso en desventaja frente a las autoridades de este último, quienes como cabeza de partido, les asistía el derecho de administrar los terrenos con el "título de sobrantes" de la comunidad de Undameo: las tierras antiguamente arrendadas. Seguramente se presentaron roces entre ambos pueblos por el manejo de los terrenos, puesto que aún no se suprimía el mandato por el cual el ayuntamiento cabecera de partido debía encargarse de administrar las tierras de comunidad de su jurisdicción. El pueblo de Undameo en atención a esta última circunstancia, y puesto que ya no contaba con la institución del ayuntamiento, decidió aprovechar la oportunidad que le brindaba la ley de reparto de 1827 para recuperar los bienes de comunidad entre sus integrantes, aunque fuese mediante la posesión privada de ellos. En este ejemplo no vemos oposición, sino aceptación a repartir aquellos terrenos que desde hacía tres décadas se encontraban en arrendamiento.

También los indígenas de Chiquimitío admitieron el reparto de su propiedad común. Lo llamativo es que tan pronto como contaron con sus fracciones de tierra y esperaron los cuatro ańos de posesión, como lo indicaba el Reglamento de 1828, algunos parcioneros se desprendieron de ellas. ${ }^{31}$ De modo que los indígenas en su calidad de propietarios plenos hacían uso del derecho de venderlos a terceros. Por lo tanto, la política de la elite de liberar la propiedad en

Historia Colonial de Michoacán, Encuentros, México, Universidad Michoacana de San Nicolás de Hidalgo, Ciesas, 1997, 227-247.

${ }^{31}$ Archivo Histórico Municipal de Morelia, siglo xix, caja 41, (1), "Autos de posesión y partición de las tierras de comunidad entre los descendientes de las primitivas familias del Pueblo de San Francisco Chiquimitío", 1828, 93 fe.; caja 6, (18), "El común de naturales del pueblo de Chiquimitío ante Gervasio Farfán, alcalde constitucional del pueblo de Tarímbaro y su jurisdicción para que se les permita vender una parte de las tierras de siembra y pastales que se les dio en propiedad hace tiempo", 6 fe., 1833; de la misma caja el expediente 19, "María Juliana Guadalupe Rodríguez, indígena del pueblo de Chiquimitío, ante Palacio Mejía, $2^{\circ}$ alcalde constitucional de Tarímbaro, informa que vendió un solar de su propiedad a Amado Aventaño en cantidad de 20 pesos de oro común”, 4 ff., 1834. También véase el expediente (48). 
manos de las corporaciones indígenas empezaba a rendir fruto. ${ }^{32}$ Así, ciertos pueblos nombraron comisiones repartidoras, elaboraron los padrones de beneficiados y la lista de terrenos para dividirlos en parcelas y distribuirlos entre los indígenas. Durante el proceso de reparto, emergieron dudas entre los comisionados, mismos que hicieron llegar al Consejo de gobierno y al Congreso del estado. Éstos por su parte propusieron y decretaron órdenes con la finalidad de aclarar y hacer realidad el reparto. En este contexto, una de las dudas giró en torno a las personas que deberían ser beneficiadas, definidas en la ley como descendientes de las "primitivas familias".

\section{LAS "PRIMITIVAS FAMILIAS" Y AVECINDADAS: BENEFICIADAS EN EL REPARTO}

Una vez iniciados los primeros trabajos de división, los comisionados repartidores e indígenas solicitaron se aclarara a que se refería la ley cuando decía que las personas agraciadas debían ser "los descendientes de las primitivas familias". Por ejemplo, en el pueblo de Parácuaro $^{33}$ la comisión realizó el registro de individuos que resultarían favorecidos. Tan pronto como se dio a conocer entre los pobladores, surgieron inconformidades de algunos jefes de familia que no fueron apuntados en la lista.

Así sucedió con Antonio, Narciso, Cirilo, Guadalupe, Eligio, Narcisa y Atanasia, de apellido Madrigal, quienes se dirigieron como "ciudadanos" ante el ayuntamiento de Apatzingan para exigir que fueran incluidos en el padrón de indígenas. Para ello, argumen-

${ }^{32}$ Otras comunidades de indígenas que procedieron al reparto fueron: Tangamandapio, Turicato y La Piedad. Consúltese: S. García Ávila, La politica liberal y las comunidades.., pp. 351-354.

33 Para 1822 el pueblo de Parácuaro, anexo de la municipalidad de Apatzingan, apenas comenzaba a reponerse después de que durante la "revolución de independencia" había sido incendiado y "destruido enteramente". Para esta fecha vivían 30 personas, de las cuales una parte había migrado a dicha localidad para emplearse en los ranchos y haciendas de la Tierra Caliente. Cuando se dio a conocer la Ley de reparto (1827), el número habitantes ya se había recuperado al calcularse cerca de 100 habitantes. Esta población optó por repartirse los terrenos de "comunidad", con el título de sobrantes, los cuales ya tenían ańos de no disponer de ellas para provecho comunal. 
taron que sus padres, Francisco Marcelo Madrigal y Agustina Teresa Salas, habían cumplido con "los servicios asi personales como de dinero [...] como indios reducidos con los demás naturales de el" ${ }^{34}$ Incluso, aseveraron que su padre en distintos momentos había ocupado el cargo de alcalde, regidor y demás cargos de república. Igualmente, los hermanos Madrigal refirieron que habían cumplido con los "servicios personales y pagos para las fiestas civiles y religiosas", por lo que pedían que se les incluyera en el padrón de beneficiados. La familia reclamó su inclusión argumentando que sus padres moraban en la vicaría de Parácuaro desde fines del siglo xviII. En efecto, en el padrón de feligreses de la parroquia de Apatzingan de 1792, se apunta que en Parácuaro vivían dos familias con apellido Madrigal, una de ellas la encabezaba Marcelino Madrigal casado con Agustina Teresa. ${ }^{35}$

Es probable que un grupo de indígenas de Parácuaro haya aprovechado la Ley de reparto para desconocer a los Madrigal como "hijos del pueblo", en virtud de problemáticas que probablemente venían de años atrás relacionadas con la posesión y el usufructo de alguna fracción de tierra. Efectivamente, desde mayo de 1826, los hermanos Madrigal se habían quejado ante el alcalde de Apatzingan de que "los Naturales de Paraquaro (de manera) autoritaria los despojaron violentamente de todo, además de las tierras que cultivaban para la solución de las familias". Cuando las autoridades de Parácuaro se percataron que la Ley de 1827 les favorecía para recuperar aquellas tierras que habían estado en arrendamiento e, incluso, las que no estaban en esa situación, no dudaron en utilizarla a su favor, además de excluir a los hermanos Madrigal en el reparto. Ello recuerda la práctica de los naturales del orden colonial de aprovechar las leyes de Indias que les favorecían para expulsar a sus opositores (mestizos o indios) que afectaran los intereses de la comunidad, o bien fueran

${ }^{34}$ Archivo Histórico del Congreso del Estado de Michoacán (en adelante AHCEM), Legislatura II: 1827-1829, caja 4, (12), Salvo que indiquemos lo contrario, la información que en adelante se maneja, proviene de este expediente.

${ }^{35}$ Archivo Histórico Casa de Morelos, padrones, 1328, (1267), "Padrón del Pueblo de Indios de Apatzingan, sus anexos, Haciendas y rancherías hecho por el brigadier don Vicente Laredo cura y juez eclesiástico". 
contrarios a la facción política de mayor fuerza. ${ }^{36}$ No sabemos en qué concluyó el pleito, pero destaca cómo dicha ley de reparto reavivó viejas conflictividades al interior de los pueblos.

De suerte que el caso de Parácuaro muestra la conformidad de indígenas por fraccionarse las tierras comunales, lo cual derivó en dudas y pleitos en torno a las personas que habrían de ser las beneficiadas por aquello de ser o no "descendientes de las primitivas familias”. Es probable que el caso referido no sea la excepción y que haya habido más ejemplos en ese sentido al aplicarse la ley de reparto de 1827.

Aparte de los problemas derivados de definir a los "descendientes de las primitivas familias", también los indígenas se preguntaron acerca del pueblo donde debían empadronarse que, provenientes de uno distinto, tenían ya algunos años de radicar en otra población. Así ocurrió en 1828 con ocho familias de Los Reyes, quienes se quejaron ante el ejecutivo del estado de que no habían sido incluidos en el padrón para el reparto de tierras, por lo que exigían participar a fin de contar con terrenos en "posesión y propiedad". ${ }^{37}$ Situación similar sucedió con ocho indios que no eran oriundos del pueblo de Guarachita. ${ }^{38}$ Uno de ellos, José Arreguín, procedente de Jaripo, tenencia de Tangamandapio, se estableció en Guarachita antes del estallido de la revolución de independencia, lugar donde contrajo matrimonio, de cuyo enlace nacieron tres hijos. En la integración de la lista, emergió la pregunta si los hermanos Arreguín, herederos de su padre, debían empadronarse en Guarachita como si fueran descendientes de las "primitivas" familias. ${ }^{39}$

El vicegobernador José Trinidad Salgado expuso ante el Consejo de gobierno que la Ley y el Reglamento no disponían nada sobre si

${ }^{36}$ Felipe Castro, Los tarascos y el imperio español, México, IIH-Universidad Nacional Autónoma de México, Universidad Michoacana de San Nicolás de Hidalgo, 2004.

${ }^{37}$ Archivo del Instituto de Investigaciones Históricas, Universidad Michoacana de San Nicolás de Hidalgo (en adelante AIIH-UMSNH), Actas del Consejo de Gobierno, año de 1828, sesión del 3 de septiembre, f. 20. núm. 29; sesión del 13 de septiembre, f. 23v; sesión del 16 de septiembre, f. 22.

${ }^{38}$ Guaracha se ubica en la cuenca del lago de Chapala, al noroeste del territorio de Michoacán.

${ }^{39}$ AHCEM, Legislatura II, 1827-1829, caja 3, (1). 
los indios de un pueblo, radicados en otro podían tener derecho al reparto, por lo que aseguró que los beneficiados debían ser los "descendientes de las primitivas familias y no de otras castas agregadas al pueblo", mismos que, además, debían cumplir con los "servicios prestados a la comunidad". Por su parte, el Consejo de gobierno fundado en el artículo $1^{\circ}$ de la Ley de 1827 reiteró que las personas por recibir un palmo de tierra eran "los descendientes de las primitivas familias", mientras que los recién avecindados lo obtendrían en el pueblo de su ascendencia. La propuesta de ley quedó de la siguiente forma: "las familias de indígenas que hubiesen emigrado del pueblo, donde tienen su ascendencia no tendrán derecho a las tierras de comunidad de aquel en que se hallan avecindados". ${ }^{40}$ Dicho de otra manera, las familias que habían salido de sus comunidades y que radicasen en otras, no tendrían derecho al reparto en el lugar donde residían, sino en el pueblo de donde provenían.

Las dudas y aclaraciones no terminaron allí. El problema de la vecindad y la ausencia no fue asunto fácil de resolver, en virtud de que el indígena que llegaba a radicar en pueblo distinto al de su origen obtenía derechos en el instante que contraía matrimonio con una persona del lugar y, además, cumplía con los pagos y servicios. La documentación generada al respecto impide conocer cómo era "el costumbre" en determinada comunidad en relación con la aceptación de la persona externa, además del tiempo requerido para adquirir los derechos de vecindad. De acuerdo con la costumbre de algunos pueblos p'urhépecha, el habitante de un pueblo que provenía de otro lugar comenzaba a tener derechos desde el momento que tomaba cargos que le encomendaba la autoridad. Incluso, se le otorgaba un terreno para la construcción de su casa si su pareja del lugar carecía de un espacio para vivir.

La duda en torno a si debían o no figurar como beneficiados aquellos indígenas que tenían algunos años de vivir en un pueblo distinto del lugar de su nacimiento fue atendida por el Consejo de gobierno. Los miembros de este cuerpo colegiado, después de intercambiar varios puntos de vista, convinieron que para tener derecho

${ }^{40}$ AHCEM, Legislatura II: 1827-1829, caja 4, (12). 
a una fracción de tierra, el jefe de familia debía cumplir el requisito de diez ańos de vecindad aunque no fueran seguidos; además de haber realizado los respectivos pagos y servicios. La iniciativa de ley fue aprobada por el Consejo de gobierno el 9 de septiembre de 1828, pero fue hasta el 19 del mismo mes que el Congreso la decretó como sigue:

$1^{\circ}$.- Las familias de indígenas que hubiesen sido admitidos en otra comunidad y hayan desempeñado por diez ańos aunque no sean continuados las obligaciones que por ésta se le ha encomendado, tendrán en el lugar donde actualmente están avecindados, repartimiento de tierras de comunidad, el mismo derecho que los hijos de ella. ${ }^{41}$

Los avecindados indígenas que no cumplieran el requisito de diez años de residencia, podían realizar el reclamo en el pueblo de su "ascendencia”, ya fuera por línea paterna o materna. En los pueblos donde ya se hubiese realizado el reparto y las familias probaran que tenían derecho a ello, se les "indemnizaría con numerario". Sin embargo, dichos ordenamientos seńalados en los artículos 2, 3 y 5 tendrían efecto sólo hasta septiembre de $1830 .{ }^{42}$ Cabe recalcar que mediante el decreto de 19 de septiembre de 1828 la elite política estatal aceptó la costumbre que privaba entre indígenas de admitir individuos o familias en sus comunidades, siempre y cuando, hubiesen cumplido con los "servicios" y "pagos" por el término de 10 años. Los legisladores así lo decretaron en virtud de las peticiones de indígenas y de los comisionados que, por conducto del prefecto, dieron parte al Consejo de gobierno. Así fue como a los indígenas provenientes de otras comunidades les reconocieron derechos de "vecindad".

No obstante el reconocimiento de la elite estatal a la costumbre de los pueblos de admitir "familias indígenas", en los meses subsiguientes se suscitaron más preguntas en relación con las personas que resultarían beneficiados en el reparto; tan fue así, que el legislativo tuvo

${ }^{41}$ AHCEM, Legislatura II: 1827-1829, caja 4, (12); Decreto de 19 septiembre de 1828, Amador Coromina, vol. 1, t. III, Recopilación de leyes.., 1886, 97.

${ }^{42}$ Ibid., p. 98. 
que recordar que los sujetos con derecho a una propiedad "plena" serían los "descendientes" de las primitivas familias y los indios avecindados que tenían diez años de residencia. Pero aquellos "que gratuitamente y por conveniencia particular han agregado los indios a sus comunidades" no debían formar parte de los beneficiados. ${ }^{43} \mathrm{En}$ particular, el decreto del 18 de noviembre de 1828 fue enfático al enunciar: "Tienen derecho al repartimiento de tierras de comunidad todos los individuos que inmediatamente desciendan de padre o madre indígenas, y ningunos otros" ${ }^{44}$ Esto fue así porque seguramente la elite estatal se percató de los problemas que traía consigo la aplicación de la Ley y el Reglamento de reparto de tierras, en especial el empuje social de la población mestiza en los pueblos. De ahí, entre otras razones, que el ejecutivo estatal con auxilio del Consejo de gobierno, haya realizado los reajustes legales a fin de transformar el modo en que los pueblos indígenas poseían y usufructuaban la tierra.

Las dudas no pararon de llegar al gobierno del estado. Una de ellas la formuló un vecino del pueblo de Los Reyes en el sentido de si podía ser beneficiado. El vicegobernador José Trinidad Salgado respondió que si

Es Indio, hijo de las primitivas familias, casado con india extrańa, o con distinta casta, no hay duda que debe obtener la parte que le toca por indio, pues desciende de las primitivas familias del Pueblo, pero los viudos no indios que fueron casados con hijos del pueblo y tuvieron hijos que se murieron, o que no los tuvieron, si deberán tener por herencia la parte que debía corresponder a su mujer, o a sus hijos... ${ }^{45}$

No hubo problema en reconocer el derecho que asistía al indígena, no obstante que estuviese casado con "india extraña" o "con distinta casta”. Las dificultades comenzaron a aflorar con aquellos

${ }^{43}$ AHCEM, Legislatura II, 1827-1829, caja 3, (1).

${ }^{44}$ Decreto de 18 de noviembre de 1828, Amador Coromina, Recopilación de leyes.., vol. 1, t. III, 1886, 110.

${ }^{45}$ AHCEM, Legislatura II, 1827-1829, caja 3, (1), cursivas mías. Véase también el Decreto de 18 noviembre de 1828, Amador Coromina, Recopilación de leyes.., 1886, vol. 1, t. III, p. 110. 
no indios que habían contraído nupcias con las mujeres del pueblo. $Y$ es que el avecindado mestizo o mulato que había contraído matrimonio con una indígena no tenía derecho a una fracción por sí, sino por conducto de su esposa, quien sí poseía el derecho a obtener una fracción de tierra. Esto último, nos lleva a plantear un asunto de importancia y que reavivó conflictos al interior de los pueblos con motivo de la aplicación de la ley de reparto: me refiero a la incursión y admisión de mestizos y demás castas en los pueblos indígenas.

Ello no fue un asunto menor, sino un problema de gran envergadura porque se trataba, ni más ni menos, que de los derechos que adquirían los mestizos y las castas que se habían avecindado en los pueblos de indios. Ya José Trinidad Salgado había puesto el tema a discusión en el Congreso Constituyente de 1825 al reconocer; en primer lugar, que las familias indígenas tenían derecho a una propiedad individual en virtud de que sus antepasados habían sido los propietarios "originarios"; en segundo lugar, al proponer que los mestizos y las castas fuesen favorecidos porque éstos habían nacido de la relación y mezcla entre indios, españoles y negros, además de que "traen su origen de aquellos (indígenas), aunque por una línea transversal". Salgado reconocía que si bien los indios tenían un "derecho más fuerte" que las castas, éstos también debían beneficiarse en el reparto en virtud de que tenían "el derecho adquirido por la vecindad". 46

El derecho de vecindad fue reclamado en viejas cabeceras de república de naturales, por ejemplo, un habitante de Uruapan de apellido Millán, defendió haber figurado "en el padrón de tributarios" y de haber gozado, al igual que los indios, de "fueros y privilegios". De igual modo, argumentó que había cumplido con los "servicios personales" al cura y al subdelegado "como sujetos a la comunidad de indios que también ellos la componían, sirviendo ya con su persona o intereses, lo mismo que los demás indios" ${ }^{47}$ Pese a estos esfuerzos de los mestizos por distinguirse como "hijos del pueblo" $y$, por lo tanto, con derecho a participar en el reparto, la elite política

${ }^{46}$ J. C. Cortés Máximo, De república de indios a ayuntamientos constitucionales, p. 317.

${ }^{47}$ AHCEM, Legislatura II: 1827-1829, caja 4, (12). 
michoacana fue enfática al sostener que las personas con derecho a una fracción de tierra eran sólo aquellas que descendían "de padre o madre indígena, y ningunos otros", como ya expusimos.

No tenemos más datos que ilustren la inclusión o exclusión del mestizo Millán, lo cierto es que los indígenas de Uruapan trataron de conservar sus tierras de comunidad. Y si se trataba de repartirlas entre los "descendientes de las primitivas familias", no dudaron en utilizar dicha ley para favorecer a su comunidad frente a los mestizos que demográficamente eran cada vez más y, además, ocupaban los espacios de poder en el ayuntamiento local. Si ya habían perdido su gobierno de "república de naturales", ${ }^{48}$ quizás no estaban dispuestos a sufrir lo mismo con sus bienes comunales, por eso se opusieron a enlistar a los mestizos en el padrón de indígenas de Uruapan. De modo que las comisiones y las comunidades, al solicitar que se aclararan sus dudas, no plantearon la anulación de la ley, sino que se resolvieran situaciones concretas relacionadas con el reparto que el Reglamento de la materia no había previsto. Por lo tanto, no vemos oposición en estos pueblos sino conformidad para proceder al reparto.

Si bien afloraron problemáticas derivadas de definir la ascendencia indígena y los derechos de vecindad durante el proceso de reparto, también surgieron preguntas relacionadas con la designación, el número y el perfil de los integrantes de las comisiones encargadas de realizar las tareas de deslinde de tierras.

\section{LA COMISIÓN REPARTIDORA}

A este respecto el artículo $3^{\circ}$ de la ley de 1827 estableció que cada "comunidad" elegiría a "pluralidad absoluta de votos una comisión compuesta de cinco individuos" ya fueran oriundos o ajenos al pueblo. ${ }^{49}$ El Reglamento de 1828 , en sus artículos que van del $1^{\circ}$ al $4^{\circ}$, ratificó la elección de los cinco individuos y añadió que éstos debían

${ }^{48}$ Jaime Hernández Díaz, "Los ayuntamientos de Michoacán en los inicios de la vida independiente: realidad y crisis", en Ayuntamientos gaditanos en México, 1820-1827, Zamora, El Colegio de Michoacán, Universidad Veracruzana, 2007, 237-265; J.C. Cortés Máximo, "Ayuntamientos gaditanos", Tzintzun, pp. 33-64.

${ }^{49}$ Amador Coromina, Recopilación de leyes.., vol. 1, t. II, 1886, 67. 
nombrarse entre los vecinos de la cabecera municipal. Esta comisión se encargaría de integrar los padrones de agraciados, medir y calcular el terreno, realizar el avalúo, hacer la cuenta de repartición y poner a cada individuo en posesión de lo que correspondiese con la indicación de señas y linderos. La comisión en consonancia con el ayuntamiento, procedería a elaborar una lista de tierras "ya sean de las que disfrutan los naturales, ya de las que están en arrendamiento con título de sobrantes de comunidad". Recordemos que las tierras a las que se referían eran las antiguamente arrendadas por los subdelegados y las que usufructuaban los indígenas (que podían ser de repartimiento o bien de ejidos). No tenemos información acerca del número de comisiones que se integraron, pero tan pronto cómo iniciaron sus tareas surgieron los primeros inconvenientes de tipo operativo consistentes en que las personas nombradas renunciaban o se apartaban para dedicarse a sus actividades habituales: la siembra y el cuidado de sus cultivos.

En ese sentido fue el informe, en agosto de 1828, que rindió la prefectura del Departamento del Sur al gobierno del estado. ${ }^{50}$ El prefecto de esta jurisdicción refirió que una vez que se elegían a los comisionados, éstos renunciaban a su nombramiento con los consiguientes problemas para designar un nuevo comité. Esto último se dificultaba en virtud de que los habitantes de los pueblos con el rango de tenencias, como lo establecía el Reglamento, debían acudir hasta la cabecera de ayuntamiento para elegir a la comisión. Ello se complicaba aún más por la distancia que había entre las cabeceras y sus anexos, sobre todo las ubicadas en la Tierra Caliente de Tepalcatepec, en la zona del Balsas y en la Sierra Costa, que comprendía la jurisdicción de la prefectura del Departamento del Sur. Desde luego, la orden de que los habitantes de las tenencias asistieran a sus cabeceras para elegir a la nueva comisión, iba en detrimento suyo porque descuidaban sus actividades agrícolas.

Para resolver ese inconveniente, el Consejo de gobierno propuso que los vecinos realizaran la elección ante los tenientes de los pue-

${ }^{50}$ Este Departamento estuvo conformado por los partidos de Uruapan, Taretan, Tacámbaro, Apatzingan, Ario y Coahuayana. 
blos, "quienes obrarán conforme a las instrucciones que les dé el Alcalde de la cabecera, y que no se les admita por ningún motivo la renuncia" ${ }^{51}$ Así fue como el 29 de octubre de 1828 el ejecutivo del estado, por recomendación del Consejo de gobierno, decretó que aquellas "comunidades de indígenas" que no podían asistir a la cabecera para nombrar la comisión respectiva por la "distancia y suma pobreza”, lo realizarían ante sus tenientes. ${ }^{52} A$ parte de la renuncia de ciertos comisionados a sus nombramientos por motivos laborales, el Reglamento en su artículo $1^{\circ}$ dispuso que la comisión se integrara de cinco individuos, sin embargo, la mayoría de los pueblos no pudo concretar el número indicado.

El secretario del Consejo de gobierno, José Ramón Sánchez, sostuvo que los problemas no eran producto del número de personas, sino encontrar hombres idóneos para desempeñar el trabajo "arduo" y "complicado", puesto que la experiencia indicaba que las comisiones nombradas carecían de toda "ilustración". Ante ello, el ejecutivo planteó que se nombraran "agrimensores examinados", esto es, individuos que tuviesen conocimientos en materia de división y deslinde, lo cual, se consideró, agilizaría el proceso de reparto. Sin embargo a principios de octubre de 1828, Antonio Chávez y Juan José Farfán, miembros del Consejo de gobierno, señalaron que el "repartimiento" por medio de agrimensores, propuesto por el gobierno del estado, afectaría a los indígenas por los excesivos pagos a que estarían sujetos, además de que resultaría complicado traer varios agrimensores de la ciudad de México. ${ }^{53}$ Ante estas consideraciones formuladas por el Consejo de gobierno, el 21 de octubre del mismo año, el ejecutivo decretó una medida extrema ya que de cinco personas que originalmente precisó el Reglamento, ahora debía nombrarse "un sujeto idóneo". ${ }^{54}$ No obstante, esta medida no resol-

\footnotetext{
${ }^{51}$ AHCEM, Legislatura II, 1827-1829, caja 3, (1). “José Ramón Sánchez, secretario del Consejo de gobierno informa a José Salgado, gobernador del Estado”.

${ }^{52}$ Amador Coromina, Recopilación de leyes.., 1886, vol. 1, t. III, Decreto del 29 de octubre de 1828 , véase artículo $1^{\circ}$, p. 107.

${ }^{53}$ AHCEM, Legislatura II, 1827-1829, caja 3, (1).

${ }^{54}$ Orden del 21 de octubre de 1828, Amador Coromina, Recopilación de leyes.., vol. 1, t. III, 1886, 100, 101.
} 
vió los problemas relacionados con el proceso de reparto, pues recuérdese que las tareas consistían, entre otras actividades, formar padrones, dividir y medir los terrenos fraccionados y entregar a cada jefe de familia la parte de tierra correspondiente "con señalamiento de señas y linderos", que de suyo implicaba demasiado trabajo para un sólo comisionado. De modo que al final se convino en que se incrementara a tres individuos, fuesen del pueblo o ciudad inmediata, pero con la condición de que al menos uno de ellos tuviese conocimientos en cuentas.

En forma paralela, el Consejo de gobierno no dejó pasar la oportunidad para advertir que el reparto de tierras no era nada "cómodo" y que las "dificultades" e "inconvenientes" bien podían haberse subsanado si "la ley hubiese prevenido que la división de tierras se hiciese en menos partes y para menos individuos, satisfaciendo al resto, su haber en dinero, único medio para practicar la partición de un terreno" ${ }^{55}$ Es interesante hacer notar la propuesta de los integrantes del Consejo, en el sentido de que el reparto de tierras debía realizarse "con menos individuos" y "en menos partes", mientras que el resto del común únicamente recibiría dinero por el derecho que le asistía a recibir una fracción de tierra.

Salvados, aparentemente, el número y el perfil de los integrantes de la comisión repartidora, otra problemática que compartieron ciertos pueblos en relación con los primeros pasos para verificar el reparto, tuvo que ver con la escasez de recursos para cubrir los gastos.

\section{ESCASEZ DE FONDOS Y "POCA TIERRA"}

Para cubrir los primeros gastos a los miembros de la comisión que se erogasen con motivo del reparto, desde el 5 abril de 1827 los diputados habían ordenado su pago a través de las arcas de comunidad en poder de los ayuntamientos. ${ }^{56} \mathrm{El}$ artículo 34 del Reglamento de 1828 confirmó la disposición del 5 de abril arriba señalado; además,

55 Ailh-umsnh, Actas del Consejo de Gobierno, año de 1828, 8 de octubre, f. 33. También puede verse en S. García Ávila, La política liberal y las comunidades..., p. 346.

${ }^{56}$ Decreto Num. 33, 5 de abril de 1827, Amador Coromina, Recopilación de leyes., vol. 1 , t. II, 1886,81 . 
estableció que si los pueblos no contaban con ello, o fuese insuficiente, se obtendrían del ramo de fondos de comunidad existentes en la tesorería del estado. Pero si los pueblos carecían de aquellos rubros, entonces los indígenas empadronados debían cubrirlo. ${ }^{57}$

El argumento de ciertas comunidades de que carecían de recursos fue uno de los inconvenientes para que no se concretara el reparto. A los pocos meses de haberse publicado el Reglamento, los reportes de algunas comisiones repartidoras enviadas a los ayuntamientos, giraban en el sentido de que los indios no contaban con fondos para satisfacer los gastos y sueldos a los encargados, porque estaban "sumamente pobres". En mayo de 1828, el prefecto del Departamento de Oriente enteró al gobierno del estado que los indios del pueblo de San Lucas, localizado en la Tierra Caliente del Balsas, no tenían fondos para los primeros pagos; los de Tuxpan, cabecera de ayuntamiento, señalaron que sus recursos eran pocos, "tan escasos que apenas cubre la dotación del maestro de escuela y sus funciones de costumbre..." ${ }^{58}$ Por su parte, los indígenas de Panindícuaro y Santa Fe del Río expusieron que no tenían "fondos y arbitrios para los gastos". Ciertos pueblos de la subprefectura de Ario, según informes del prefecto del Departamento del Sur con sede en Uruapan, ${ }^{59}$ expusieron que a falta de dinero para pagar los sueldos a los repartidores, éstos renunciaban y se apartaban para dedicarse a sus actividades agrícolas habituales, necesarias para "la manutención de sus familias". En suma, dicho conjunto de pueblos expusieron que no disponían de recursos o que eran "sumamente pobres" como para asumir todo el gasto que implicaba el proceso de reparto. Este fue el argumento de ciertos pueblos ante la presión de la autoridad estatal de practicarse el reparto.

Otras comunidades, además de la falta de recursos, sostenían que tenían poca tierra para repartir, y la que poseían era de "poco valor". Así lo expresaron los indígenas de Tararameo, tenencia adherida al ayuntamiento de Cuitzeo. Los tarascos de Tarecuato ex-

${ }^{57}$ Ibid., p. 122.

${ }^{58}$ AHCEM, Legislatura II, 1827-1829, caja 3, (1).

${ }^{59}$ AHCEM, Legislatura II, 1827-1829, caja 3, (1). 
pusieron la "imposibilidad de hacer el reparto por falta de auxilios y poco valor de las tierras para sufragar los gastos que se eroguen". ${ }^{60}$ Es probable que los terrenos de Tarecuato no hayan sufrido la acometida de las "reformas borbónicas" como otros pueblos, lo cual puede darnos pauta para indicar la negativa al reparto de sus bienes de comunidad. Es decir, que el pueblo de Tarecuato no tuvo problemas a raíz de la política borbónica de arrendamiento de tierras, por el contrario, poseía y seguía usufructuando la mayor parte de sus tierras en forma comunal. De suerte que cuando vino la orden estatal de que se dividieran, no permitieron que se alterara la costumbre vigente de usufructo y posesión de las tierras comunales, de ahí que hayan justificado falta de recursos y poco valor de la tierra para oponerse al reparto.

Por otro lado, el proceso de reparto se retrasó porque las tierras se encontraban en litigio, hipotecadas y arrendadas. A éste último respecto, el reglamento en su artículo 27 aclaró que si los bienes de comunidad se encontraban arrendados, de todos modos se realizaría el reparto, solo que los indios beneficiados no entrarían de inmediato en la posesión de sus parcelas, sino hasta que se cumpliese el arriendo; mientras tanto, la renta que habría de pagar el arrendatario se distribuiría entre los distintos propietarios. Esta disposición favoreció a los arrendatarios porque podían continuar con el usufructo de las tierras de comunidad pagando la renta a los indígenas. Y éstos sólo entrarían en posesión de ellas una vez finalizado el arriendo. Es probable que la comunidad de indígenas al ver que no podían recuperar sus bienes hasta ese momento arrendados, hayan decidido repartirse las tierras y disfrutar, cuando menos, las rentas por la fracción de tierra adjudicada a cada comunero.

Así, los pueblos que admitieron el reparto de sus tierras fueron aquellos que tenían problemas relacionados con el arriendo de las mismas. Recordemos que en los últimos lustros del siglo XviII, algunas comunidades habían sufrido la política borbónica de arriendo de sus bienes lo que significó la pérdida de una parte de sus tierras. Para 1827 y 1828 algunos representantes de los pueblos al ver que

${ }^{60}$ AHCEM, Legislatura II, 1827-1829, caja 3, (1); Legislatura II: 1827-1829, caja 4, (12). 
sus terrenos se mantenían en arriendo y que era difícil su recuperación, decidieron repartírselos. Aunque en un primer momento no se les dio posesión, sí podían gozar de las rentas, recursos que desde antes de iniciada la guerra entre insurgentes y realistas se canalizaban a las arcas reales y, luego, en el México independiente, a la tesorería del estado. Por lo tanto, era el tiempo de recuperarlas a través de la Ley de reparto de 1827 y su Reglamento de 1828.

Pero así como ciertos pueblos indígenas se repartieron las tierras, anteriormente arrendadas por los subdelegados, otros se opusieron. Por ejemplo, los de Tinguïndín, Coalcomán, ${ }^{61}$ Tarímbaro ${ }^{62}$ y Opopeo pidieron a la legislatura estatal que se les exceptuara de aplicar la Ley de $1827 .{ }^{63}$ Los tres primeros eran cabezas de municipalidad, y aunque eran gobernados por el ayuntamiento, la comunidad de indígenas que sobrevivía en las cabeceras se regía de acuerdo a su antigua forma de gobierno, y lo hacían con base en el dominio corporativo de sus tierras comunes. En particular, llama la atención el pueblo de Opopeo porque en 1767 el alcalde y su común participaron en los "tumultos", motivo por el cual se les prohibió la elección de alcalde y demás oficiales, designando en lugar de ellos, a un "comisario" que tenía como función principal la recaudación de los tributos. En 1792, los bienes comunes arrendados de Opopeo consistían en los puestos del Tepetate y Susipichi que redituaban 29 pesos anuales. ${ }^{64} \mathrm{Si}$ tomamos como válido que únicamente se arrendaron dichos terrenos, se puede inferir que este pueblo no resultó tan afectado por la política borbónica de arriendo de tierras, a dife-

${ }^{61}$ Gerardo Sánchez Díaz, "La Comunidad nahua de Santiago Coalcomán. Reparto y resistencia en el siglo XIX", en Los indigenas y la formación del Estado Mexicano en el siglo XIX, Morelia, Michoacán, México, IIH-umSNAH, 2008, 151.

${ }^{62}$ Para más detalles de los impedimentos para que se realizara el reparto en las tierras de comunidad de los indios de Tarímbaro consúltese mi artículo: "La comunidad de Tarímbaro. Gobierno indígena, arrendamiento y reparto de tierras, 1822-1884”, en Carlos Paredes Martínez y Marta Terán, coords., Autoridad y gobierno indígena en Michoacán. Ensayos a través de su historia, México, El Colegio de Michoacán, Ciesas, INAH, UMSNH, 2003, 441-468.

${ }^{63}$ AHCEM, Legislatura Iv: 1831-1833, caja 3, (5), "Inventario de la $5^{\circ}$ Comisión de Gobernación".

${ }^{64}$ Inspección Ocular en Michoacán. Regiones centraly sudoeste, Introducción y notas de José Bravo Ugarte, México, Editorial Jus, 1960, 147. 
rencia de otras cabeceras de república de indios, que habían perdido haciendas y ranchos que en renta producían más de 400 pesos anuales. ${ }^{65}$ Por lo tanto, la cantidad de tierra arrendada y la problemática agraria producto del arriendo de la misma, incidió en el comportamiento de los pueblos indios a favor o en contra de transformar la costumbre de poseer y usufructuar sus bienes de comunidad, tanto las que se habían arrendado como las que no. Lo llamativo es que los pueblos no plantearon abolir la Ley de 1827, sino que se les excluyese de aplicarla.

En resumen, algunos pueblos como Chiquimitío y Undameo realizaron el reparto de sus propiedades; otros más como Tuxpan, San Lucas, Santa Fe del Río y Panindícuaro nombraron comisiones, pero por la aparente falta de fondos para cubrir los primeros gastos, el proceso de reparto se detuvo; otro grupo de pueblos se toparon con problemas y dudas para aplicar la ley, sobre todo, en torno a los criterios para determinar las personas con derecho a una fracción de tierra. Así sucedió con las comunidades indígenas de Jaripo, Parácuaro y Los Reyes.

\section{Conclusiones}

La elite política del estado de Michoacán, en un primer momento, buscó resolver el problema de posesión y usufructo de los bienes de comunidad vigentes en los pueblos, a través de la ley de reparto de 1827. Con ésta, el gobierno del estado devolvió jurídicamente dichos terrenos a los indígenas, política mediante la cual los ayuntamientos ya no tendrían injerencia, ni manejo sobre ellos. Con esa ley se propuso fraccionar una parte del total de las tierras comunales, pero con el Reglamento formulado en 1828, la mayoría de ellas se dispusieron para el reparto con el fin de crear pequeńas propiedades al incluirse los ejidos y los de repartimiento, excepto los de fundo legal.

${ }^{65}$ Véase, por ejemplo, los pueblos de Tzintzingareo, Queréndaro, Irimbo en Ramón Alonso Pérez Escutia, Historia de la región de Irimbo, México, H. Ayuntamiento de Irimbo-Balsal editores, 1988, 162-171. 
Al ordenarse el reparto, varios pueblos no tenían en su poder los antiguos bienes de comunidad, por lo tanto, la comunicación de que volvían a sus manos fue recibida con regocijo. Las autoridades y el común pensaron que era el momento para hacerse de aquellas tierras que desde la implementación de los Reglamentos Borbónicos de Comunidad habían salido de su control. Visto desde esta perspectiva, se entiende la aceptación de los indígenas por repartirse las tierras de comunidad. Y más todavía si consideramos las dinámicas de rivalidad entre facciones indígenas o bien de problemáticas de éstos con vecinos mestizos por la posesión y el usufructo de los bienes comunes antes arrendados. Asuntos que además ocurrieron en escenarios caracterizados por la escasez de tierras para la agricultura.

A raíz de la presencia de actores indígenas y mestizos que no eran originarios de los pueblos en los cuales se realizaría el reparto, además de los propios recovecos de la legislación, los indígenas y los comisionados solicitaron al gobierno del estado que se atendieran las dudas que se habían originado durante los primeros trabajos de división. Una de ellas fue en relación con admitir indígenas y no indígenas en el padrón de beneficiados, por aquello de que los sujetos con derecho al reparto debían ser de las "primitivas familias". La autoridad indígena o el común vinculado a la comisión repartidora utilizó la ley en dos sentidos: para defender el carácter "indio" de su pueblo y para reconocer como únicos agraciados a los "descendientes de las primitivas familias de indígenas". Ésta fue la estrategia que los indígenas utilizaron para sacar de la jugada a los "naturales" y mestizos que provenientes de otros pueblos de indios buscaban hacerse de parcelas o, bien, confirmar las que de hecho poseían.

Los indios recién avecindados en los pueblos que realizaron el reparto, solicitaron su registro en el padrón de beneficiados. Ante ello, el ejecutivo del estado resolvió que se enlistaran en los padrones si habían adquirido los derechos de vecindad. Así fue como la elite estatal reconoció la costumbre de permitir la vecindad de personas indígenas en otros pueblos, incluso de los mestizos, siempre y cuando estuviesen casados con un "hijo del Pueblo" y hubiesen cumplido con los pagos y los servicios para mantener el ciclo festivo civil y religioso de la comunidad. 
Lo llamativo de aquellos pueblos que verificaron el reparto y, en específico, los indios favorecidos, fue que tan pronto como recibieron la fracción de tierra y esperaron el tiempo de posesión que marcaba la ley, la vendieron a terceros como propietarios "legítimos". Por lo tanto, la idea de la elite política de crear propietarios plenos, capaces de disponer de sus parcelas como quisiesen, al grado de poderla vender a personas del exterior, había comenzado. De suerte que la Ley de 1827 inició el proceso de cambio en torno a la posesión y usufructo de tierras entre indígenas al abrirse el canal para venderlas como propietarios "absolutos".

Así como ciertos pueblos procedieron al reparto, otros se opusieron a ello. A esto último, la oposición de las comunidades indígenas se expresó previa ejecución de la ley de reparto y durante los primeros trabajos de división. El objetivo de la Ley de 1827 de crear propietarios plenos se cumplió parcialmente en virtud de que había pueblos en los que pesaba más la tradicional posesión y usufructo común de la tierra. Y justo el carácter corporativo de la propiedad, vigente en la sociedad indígena marcó su reacción y definió su postura ante la ley de reparto. De ahí los comunicados de los indígenas de oponerse a la parcelación de las tierras con el argumento de que tenían poca tierra o, bien, planteando que carecían de recursos para los gastos de reparto.

\section{Archivos}

AIIH-UMSNH Archivo del Instituto de Investigaciones HistóricasUniversidad Michoacana de San Nicolás de Hidalgo, Actas del Consejo de Gobierno, 1828.

AHCEM

Archivo Histórico del Congreso del Estado de Michoacán, Legislatura II: 1827-1829, caja 4; Legislatura Iv: 1831-1833, Caja 3.

AHCM

Archivo Histórico Casa de Morelos, Padrones, caja 1328.

AHMM

Archivo Histórico Municipal de Morelia, siglo XIX, cajas 6 y 41 . 


\section{BIBLIOGRAFÍA}

Abad y Queipo, Manuel, Colección de escritos, Estudio introductorio y notas de Guadalupe Jiménez Codinach, México, Consejo Nacional para la Cultura y las Artes, 1994.

Actas y decretos del Congreso Constituyente del Estado de Michoacán, t. II, Compilación, prólogo y notas de Xavier Tavera Alfaro, Morelia, Universidad Michoacana de San Nicolás de Hidalgo, 1975. Aldana Rendón, Mario, "La privatización de los terrenos comunales en Jalisco. Los primeros pasos. 1821-1833”, Alejandra García Quintanilla y Abel Juárez, coords., Los lugares y los tiempos. Ensayos sobre las estructuras regionales del siglo XIX en México, México, Consejo Mexicano de Ciencias Sociales, A.C., Universidad Veracruzana, Universidad Autónoma de Nuevo León, Editorial Nuestro Tiempo, 1989, 50-82.

Arrioja Díaz Viruell, Luis Alberto, "La desamortización de la propiedad comunal en la Sierra Mixe (Oaxaca): El caso de San Cristóbal Chichicastepec y Santa María Mixistlán, 18561863” en Carlos Sánchez Silva, coords., La desamortización civil en Oaxaca, México, Universidad Autónoma "Benito Juárez” de Oaxaca, Universidad Autónoma Metropolitana, 2007, 141-146.

Castro, Felipe, "Undameo: La contraofensiva agraria de una comunidad en el siglo XviII" en Carlos Paredes Martínez, coord., Historia y sociedad. Ensayos del seminario de Historia Colonial de Michoacán, Encuentros 3, México, Universidad Michoacana de San Nicolás de Hidalgo, Ciesas, 1997, 227-247.

, Los tarascos y el imperio español, México, IIH-Universidad Nacional Autónoma de México, Universidad Michoacana de San Nicolás de Hidalgo, 2004.

Coromina, Amador, Recopilación de leyes, decretos, reglamentos y circulares expedidas en el estado de Michoacán, vol. I, Morelia, Imprenta de los Hijos de I. Arango, 1886.

Cortés Máximo, Juan Carlos, "La comunidad de Tarímbaro. Gobierno indígena, arrendamiento y reparto de tierras, 1822-1884" en Carlos Paredes Martínez y Marta Terán coords., Autoridad 
y gobierno indígena en Michoacán. Ensayos a través de su historia, México, El Colegio de Michoacán, Ciesas, INAH, UMSNH, 2003, 441-468.

, De república de indios a ayuntamientos constitucionales: pueblos cabeceras y sujetos de Michoacán, 1740-1831, Zamora, Tesis de Doctorado en Historia, El Colegio de Michoacán, 2005.

, "Ayuntamientos gaditanos: separación y sujeción de los pueblos indios de Michoacán, 1820-1828”, en Tzintzun, núm. 45, Morelia, enero-junio de 2007, 33-64.

, "Separación de sujetos, guerra insurgente y ayuntamientos gaditanos: los pueblos indios en el Oriente de Michoacán, 17501824” en Moisés Guzmán Pérez, coord., Imaginarios, guerra y nación, México, Universidad Michoacana de San Nicolás de Hidalgo, 2007, 77-124.

Demelas Bohy, Marie Danielle, "La desvinculación de las tierras comunales en Bolivia, siglos xIX-Xx" en Han-Jürgen Prien y Rosa María Martínez de Codes, coords., El proceso..., pp. 129-155.

EsCRICHE, Joaquín, Diccionario razonado de legislación y jurisprudencia, tomos I y II, México, Librería de la Vda. De C. Bouret, 1920.

Florescano, Enrique, "El problema agrario en los último años del virreinato, 1808-1821", en Problemas agrarios y propiedad en México, siglos XVIII y XIX, Lecturas de Historia Mexicana 11, Introducción y selección de Margarita Menegus Borenemann, México, El Colegio de México, 1995, 22-55.

, Origen y desarrollo de los problemas agrarios de México, 1500-1821, Séptima edición, México, Era, 1984, 131-158.

Franco Mendoza, Moisés, "La desamortización de las tierras de las comunidades indígenas de Michoacán" en Pedro Carrasco, coord., La sociedad indígena en el centro y occidente de México, Zamora, El Colegio de Michoacán, 1986, 169-188.

, La ley y la costumbre en la cañada de los once pueblos, Zamora, El Colegio de Michoacán, 1997.

García Ávila, Sergio, "Desintegración de las comunidades indígenas de Morelia", en Estudios de historia moderna y contemporánea de México, vol. xv, 1992, 47-64.

, La politica liberaly las comunidades indígenas en Michoacán: 
de las Reformas Borbónicas a la primera república federal, México, unam, Facultad de Filosofía y Letras, Tesis de Doctor en Historia, 2006.

GuTIÉRREZ, Ángel, Las comunidades agrarias michoacanas. Siglos XIX y XX, Morelia, Universidad Michoacana de San Nicolás de Hidalgo, Archivo Histórico, 1998.

Hera, Alberto de la, "Precedentes ilustrados del proceso desvinculador y desamortizador de bienes de manos muertas" en Han-Jürgen Prien y Rosa María Martínez de Codes, coords., El proceso..., pp. 77-96.

Hernández Díaz, Jaime, "Los ayuntamientos de Michoacán en los inicios de la vida independiente: realidad y crisis" en, Ayuntamientos gaditanos en México, 1820-1827, Zamora, El Colegio de Michoacán, Universidad Veracruzana, 2007, 237-265.

KNowlton, Robert J., "La división de las tierras durante el siglo XIX: el caso de Michoacán" en Margarita Menegus, Problemas agrarios..., p. 124.

Lira González, Andrés, Comunidades indígenas frente a la ciudad de México, México, El Colegio de Michoacán, El Colegio de México, 1983.

Menegus, Margarita, ed., "Introducción”, en Problemas agrarios y propiedad en México, siglos XVIII y XIX, Lecturas de Historia Mexicana 11, México, El Colegio de México, 1995, IX-Xxx.

"La desamortización de bienes comunales y municipales en el Valle de Toluca (1800-1854)", en Siglo XIX. Cuadernos de Historia, ańo IV, núm. 12, mayo-agosto de 1995, 7-27.

, Los indios en la historia de México. Siglos XVI al XX: balance y perspectivas, Colección Herramientas para la Historia, México, Centro de Investigación y Docencia Económicas, Fondo de Cultura Económica, 2006.

, La Mixteca Baja. Entre la revolución y la reforma. Cacicazgo, territorialidad y gobierno. Siglos XVIII-XIX, México, Universidad Autónoma Benito Juárez de Oaxaca, Universidad Autónoma metropolitana-H., Congreso del Estado de Oaxaca, 2009.

Martínez de Lejarza, Juan José, Análisis Estadístico de la provincia de Michoacán en 1822, Colección "Estudios Michoacanos" IV, 
2a edición, Introducción y notas de Xavier Tavera Alfaro, Morelia, Fímax Publicistas, 1974 [1824].

Ortiz Peralta, Rina, "Inexistentes por decreto: Disposiciones legislativas sobre los pueblos de indios en el siglo xix. El caso de Hidalgo", en Antonio Escobar O., coord., Indio, nación y comunidad en el México del siglo XIX, México, Centro de Estudios Mexicanos y Centroamericanos, Ciesas, 1993, 153-169.

Pérez Escutia, Ramón Alonso, Historia de la región de Irimbo, México, H. Ayuntamiento de Irimbo-Balsal editores, 1988.

PIEL, Jean, "Problemática de las desamortizaciones en Hispanoamérica en el siglo XIX (algunas consideraciones desde el punto de vista socioeconómico y, por tanto, ideológico)”, en Han-Jürgen Prien y Rosa María Martínez de Codes, coords., El proceso..., pp. 97-128.

Prien, Han-Jürgen y Rosa María Martínez de Codes, coords., El proceso desvinculador y desamortizador de bienes eclesiásticos y comunales en la América Española. Siglos XVIII y XIX, Cuadernos de Historia Latinoamericana núm. 7, Ámsterdam, Asociación de Historiadores Latinoamericanistas Europeos, 1999.

SAmudio A., Edda O., "La transformación de la propiedad comunal en Venezuela y Colombia a través del proceso de desvinculación de bienes" en Han-Jürgen Prien y Rosa María Martínez de Codes, coords., El proceso..., pp. 157-188.

SÁnchez DíAz, Gerardo, El suroeste de Michoacán. Estructura económico-social 1821-1851, Colección Historia Nuestra 2, México, Universidad Michoacana de San Nicolás de Hidalgo, 1979. , "La comunidad nahua de Santiago Coalcomán. Reparto y resistencia en el siglo XIX", en Los indígenas y la formación del Estado mexicano en el siglo XIX, Morelia, IIH-UMSNH, 2008.

TERÁN, Marta, ;Que muera el mal gobierno! Las reformas borbónicas en los pueblos michoacanos y el levantamiento indígena de 1810, México, El Colegio de México, Tesis de Doctorado en Historia, 1995. Tomás y VAliente, Francisco, "Reflexiones finales: entre el balance, la crítica y las sugerencias”, en Desamortización y Hacienda Pública, t. II, Madrid, Ministerio de Agricultura, pesca y alimentación, 1986. 
YAsumura, Naoki, "El proceso de civilización desde abajo: el caso de un pueblo del bajío michoacano a finales de la colonia", texto presentado por el autor para su discusión en la reunión del Grupo K’waniskuyarani de Estudiosos del Pueblo Purhépecha, en el Ex Colegio Jesuita de Pátzcuaro, el 26 de enero de 2008.

FeCHA DE RECEPCión DEL ARTículo: 16 de febrero de 2010 FECHA DE RECEPCIÓN DE LA VERSIÓN FINAL: 22 de agosto de 2012 